\title{
A Look at the Effects of Japanese Public School Establishment on Taiwan's Ancestral Ethnic Group Distribution: 1901-1926
}

\author{
Yenhao Huang \\ National Chengchi University \\ Email: broadinterior12@gmail.com
}

How to cite this paper: Huang, Y. (2021). A Look at the Effects of Japanese Public School Establishment on Taiwan's Ancestral Ethnic Group Distribution: 1901-1926. Current Urban Studies, 9, 144-157. https://doi.org/10.4236/cus.2021.91009

Received: November 25, 2020

Accepted: March 22, 2021

Published: March 25, 2021

Copyright $\odot 2021$ by author(s) and Scientific Research Publishing Inc. This work is licensed under the Creative Commons Attribution International License (CC BY 4.0).

http://creativecommons.org/licenses/by/4.0/

\begin{abstract}
This article discusses about the effects of public school education on ethnic group distribution in Taiwan during the Japanese colonial period, with Changhua Plain in central Taiwan as an example. Many Han Chinese migrated to Taiwan from various coastal areas in Southeast China under the rule of Qing dynasty (1684-1895). The different ethnic groups were distributed in such a way that populations from the same ancestral home lived together while those of different descent became segregated. Transitioning into the Japanese colonial period in 1895, did the promotion of Japanese education assimilate different ancestral ethnic groups in Taiwan and change their distribution on the island? To answer this question, this article starts by organizing the 1901 and 1926 distribution of ancestral ethnic groups across 27 Changhua Plain areas in central Taiwan, as well as quantifying the levels of ethnic group distribution by the Gini coefficient. This is followed by applying difference-in-differences estimation to examine the effects of Japanese public school education on ancestral ethnic group distribution.
\end{abstract}

\section{Keywords}

Difference-in-Differences Estimation, Ethnic Group Distribution, Public Schools Establishment, Han Chinese Cultural Features

\section{Introduction}

Many Han Chinese migrated to Taiwan from southeast China coast during the Qing rule period. It was not until 1895 when Taiwan was ceded and introduced to Japanese government did the relationship between Taiwan and southeast China coast gradually decline. During the early Japanese colonial period, Han 
Chinese features and old customs in Taiwan such as head-shaving, foot-binding, and opium were immediately abolished. Regarding the land system, the Han Chinese immigrants' long-existing dual-landlord system was also revoked, establishing small tenant rights as actual landlords. As for the monetary system, the Han Chinese's traditional silver dollar system was restructured. The silver dollar flow was prohibited through the Bank of Taiwan's bank notes exchangeable for gold yuan notes (Tu, 1975). All of the above practice can be perceived as revolutionary changes imposed by the Japanese on Taiwan's traditional Han Chinese economy and society. On the other hand, these practices can also be regarded as the Japanese abolishment of Han Chinese features in Taiwan.

In Taiwan, the distribution of ancestral ethnic groups is a unique Han Chinese feature that represents the local residents' identification with their ancestral home on the Chinese southeast coast. According to a 1901 survey, most of the immigrants from China's southeast coast came from Zhangzhou, and Quanzhou in Fujian, and Guangdong. ${ }^{1}$ Hence they can be roughly divided into Zhangzhou, Quanzhou, and Guangdong ethnic groups (the Guangdong ethnic group recognized by the Japanese is the present-day Hakka). ${ }^{2}$ During the Qing dynasty, ethnic group classification occurred frequently in Taiwan. Conflicts such as the Zhang-Quan feud and Fujian-Guangdong feud all reflected Taiwanese residents' values and identification with their hometown identities. As a result of over two centuries of population interactions in the Qing-ruled Taiwan, most of the Quanzhou populations resided near seaports, while most Zhangzhou populations settled in inner mountains; Guangdong descendants often arrived later and lived adjacent to the indigenous people (Lin, 1870). This led to the formation of an ancestral home-based ethnic group distribution.

Moving into the Japanese colonial period, it is commonly agreed that 1905 marks the Japanese government's completion of capitalist infrastructure in Taiwan (Tu, 1975). In addition to the above mentioned abolishment of head-shaving, foot-binding, opium, dual-landlord system, and the issuance of bank notes, the Japanese government also established public schools across Taiwan to deliver assimilation-oriented Japanese education to Taiwanese children. Among the many assimilation policies for Taiwan, Japanese education was the primary means to achieve assimilation. During the Japanese colonial period, Japanese contemporary education was generally implemented and introduced to Taiwan through the state power (Yanaihara, 1929). For example, Isawa Shuji, the extreme assimilationist and first Chief of Education Bureau at the Government-General of Taiwan once said, "Right now the most important job is to teach Japanese to the Taiwanese people". ${ }^{3}$ Isawa Shuji's comment can be interpreted as an intention to ${ }^{1}$ In 1901, about $97 \%$ of the Taiwan population came from the ancestral home of Fujian's Zhangzhou, Quanzhou, and Guangdong on China's southeast coast (Hsu, 2003).

${ }^{2}$ The geographic locations of Hakka groups in the southeast China coastal areas were not limited to the Guangdong province. Hakka groups from Fujian province had also migrated to Taiwan.

${ }^{3}$ Rokusaburo Mochiji, the successor of Isawa Shuji once commented Shuji's Japanese education as an extreme assimilationist (Chen, 2006). 
assimilate Taiwanese children into Japanese through Japanese public school education (Chen, 2006).

However, the process of promoting assimilation policies through public schools may take away Taiwan's original traditions and culture. ${ }^{4}$ In other words, we argue that Japanese public school education in Taiwan had an implication of weakening or eliminating Han Chinese cultural features from the Qing rule. Under Japanese public school education, people's general understanding about Chinese ancestral home could be weakened from being exposed to such education at a young age, and this could go on to change ancestral ethnic group distribution. Therefore, we ask the question of whether the active promotion of Japanese education by the Japanese government assimilated different ancestral ethnic groups and changed their distribution in Taiwan. To answer this question, we use Changhua Plain in central Taiwan, an area covering present-day Changhua County, as the research subject. Then the difference-in-differences approach is also applied to discuss the above question.

This article is structured as follows: Section 2 contains an introduction to Taiwan's ethnic group distribution during the Japanese colonial period, with an estimation of the levels of ethnic group distribution clustering. Section 3 will present an econometrics model with the difference-in-differences estimation, which suggests that Japanese public school establishment did not significantly affect ethnic group distribution. There is a conclusion in the final section at the end.

\section{Data Compilation, Ancestral Ethnic Group Distribution, and Public School Establishment}

The ancestral ethnic group distribution in Taiwan during the Japanese colonial period can be induced from Investigations on Formosa Development and History in 1901 and Investigation of Han Ancestral Home in Taiwan in 1926. We focus on Changhua Plain in central Taiwan as the geographic range, which encompasses the area of present-day Changhua County for geographic considerations. Changhua Plain is a relatively comprehensive administrative district. It is bound by Dadu River to the north, Zhuoshui River to the south, neighboring Taiwan Strait on the east, and adjacent to the Bagua Mountain Divide on the west. In the early days when traffic was relatively inconvenient, Changhua Plain could be regarded as an independent area for research purposes.

As for data time points, we collects ethnic group distribution data in Changhua Plain from 1901 and 1926, and compiles the information into two sets of panel data based on the 1926 administrative districts known as "gaishou". Why was 1926 chosen as a basis? It is important to first understand the background in the publication of these two books: Investigations on Formosa Development and ${ }^{4}$ This idea is similar to that of Komagome (1996), who believed that Taiwanese would inevitably resist the Japanese language and culture during the assimilation process. This would further endanger the traditional position of Taiwan's original language and culture. 
History and Investigation of Han Ancestral Home in Taiwan.

The content of Investigations on Formosa Development and History is a handwritten report of investigation results requested by the Government-General of Taiwan (1902), the highest governing body in Taiwan during the Japanese colonial period. This book was never published. In contrast, the 1926 Investigation of Han Ancestral Home in Taiwan was compiled and published by the Investigation Office of Government-General of Taiwan (1928). These two books vary quite a bit in regard to the survey time points and content formats. Their greatest variation lies in different survey areas so that it makes data compilation more challenging. In order to organize the panel data into two time points, the survey areas in these two sets of data must be integrated to provide a common ground for comparison. Since the administrative districts in 1926 are roughly similar to the present-day administrative divisions of "townships and districts," we use the 1926 "gaishou" as a basis for integration. By doing so, not only can the two sets of historical data be compared at once, but a closer link to modern administrative districts can also be provided.

Nevertheless, we were limited by an incomplete collection of historical statistics data as it could only find the data of ethnic group distributions in 1901 and 1926 for the time being. Fortunately, the historical background of these two sets of statistical data can still help provide an understanding about some of the features at those times. In 1901, Taiwan had only been conceded by the Qing Empire for six years. The Japanese power had not yet gained complete control over Taiwan; hence the data should be able to reflect Taiwan's ethnic group distribution during the early Japanese colonial period. In contrast, the Japanese governance was stable in 1926 as Japanese capitalism had completely dominated Taiwan. ${ }^{5}$ As Hsu (2003) described that "In terms of survey time, the 1901 data reflect the ancestral ethnic group conditions from the late Qing dynasty to early Japanese colonial period, whereas the 1926 data demonstrate the conditions after Japan established stable governance in Taiwan".

After processing Changhua Plain's 1901 and 1926 ethnic group distribution data and compiling them into two sets of panel data, we continues by explaining the population proportion of ancestral ethnic groups. There are four representative districts in Central Taiwan's Changhua Plain during the Japanese colonial period: Changhua Street, Yuanlin Street, Xiushui Village, and Tianwei Village. With regard to "gaishousei," the administrative district system during the Japanese colonial period, the former two administrative areas were divided as "streets" (gai) to represent more prosperous areas. The latter two "villages" (shou) implied that they were less prosperous than the former areas (Taiwan Self-Governance Association, 1943). In addition, the objective of this article to examine the effects of Japanese public school education on ancestral ethnic group distribution can be achieved by making a comparison between these four

${ }^{5}$ At the time Taiwan was developing the rice and sugar economy then becoming state monopoly capitalism ( $\mathrm{Tu}, 1975)$. 


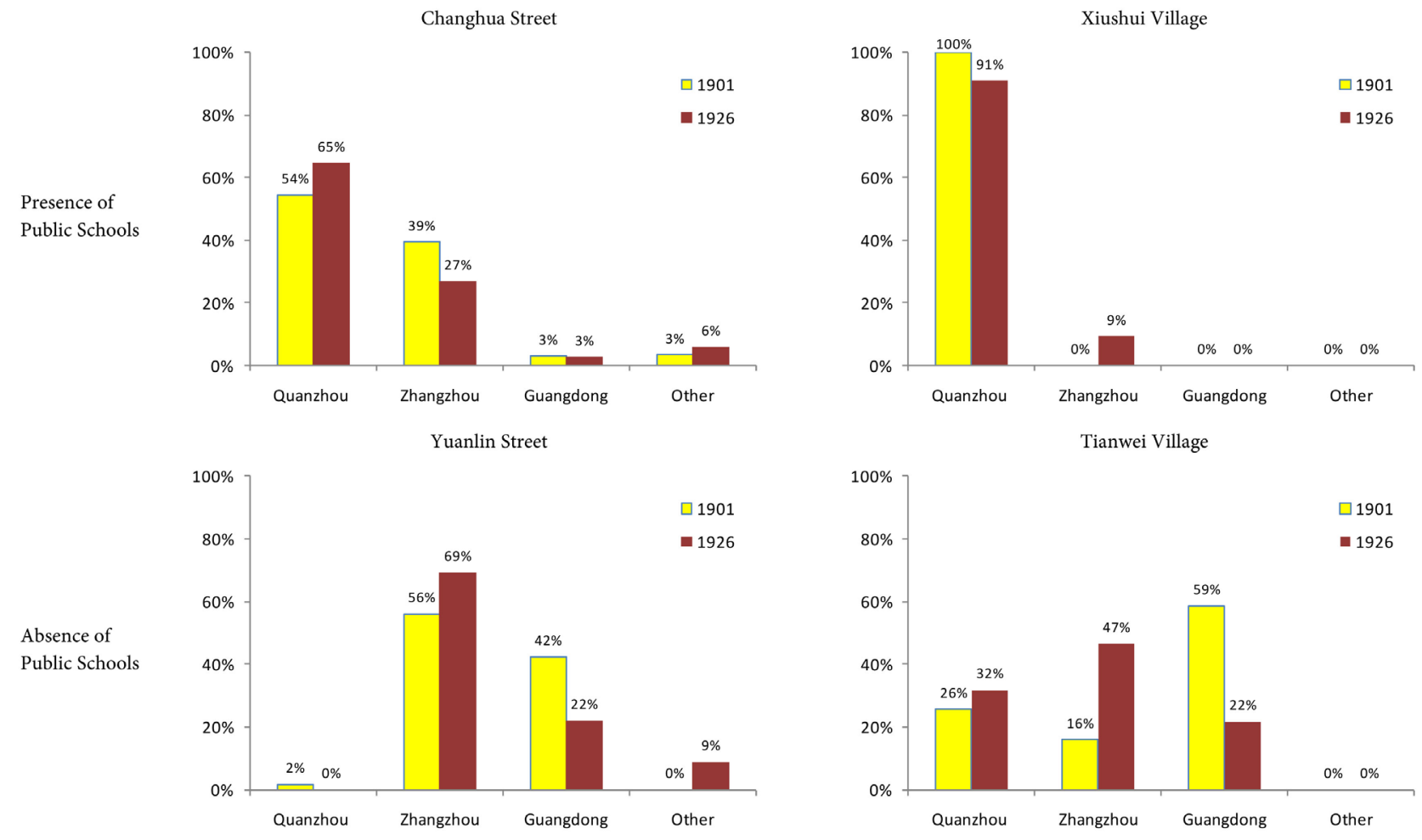

Figure 1. Population proportion of ancestral ethnic group distribution across four Changhua districts: 1901 vs. 1926.

${ }^{6}$ Changhua Public School was established on Changhua Street in 1898, at the present-day location of Changhua Confucian Temple. In Xiushui Village, Lugang Public School Yaxing Branch was established in 1899, which is the present-day Xiushui Elementary School. 
and an increase in Zhangzhou population, demonstrating a dispersed trend in ancestral ethnic group distribution.

Next, let us shift the focus to Yuanlin Street and Tianwei Village with no public school establishment during the early Japanese colonial period. In 1901, Yuanlin Street was most heavily populated by people from Zhangzhou followed by those from Guangdong; the proportion of people from Quanzhou was relatively minimal. By 1926, the proportion of Zhangzhou population grew rapidly with an obvious decline in the Guangdong population. The Quanzhou population was not observed, yet there was a rise in other ancestral ethnic groups that could not be ignored. It is worth noting that changes in the proportion of ancestral ethnic groups on Yuanlin Street could have cancelled each other out. Hence it is difficult to confirm whether the ancestral ethnic group distribution was dispersed or not. The same pattern was found for Tianwei Village, where the changes between 1901 and 1926 followed a slight increase in Quanzhou population, a sharp increase in Zhangzhou population, and a sharp decrease in Guangdong population. Therefore, it is also difficult to confirm the trends of ancestral ethnic group distribution in Tianwei Village.

In places where public schools were established, Changhua Street had become a more centralized ancestral ethnic group distribution while Xiushui Village had become a relatively dispersed distribution. In contrast, the ancestral ethnic group distribution in Yuanlin Street and Tianwei Village-places without public schools-cannot be easily summed up in a word. Under such circumstances, any subjective judgments may be biased. Therefore, we need an objective index to describe the level of ancestral ethnic group distribution. Based on advices from the U.S. Census Bureau, the level of ethnic group distribution may be calculated by using the dissimilarity index, Gini coefficient, entropy, and Atkinson index. However, only the Gini coefficient and Atkinson index can meet the four criteria of transfer principle, compositional invariance, size invariance, and organizational equivalence (Iceland et al., 2002). Since the Gini coefficient calculation is originated from the Lorenz curve, it is more intuitive and widely used by researchers than the Atkinson index. Thus, we use the Gini coefficient for measuring the degree of centralization of ancestral ethnic group in demography. Table 1 shows the Gini coefficients for ancestral ethnic group distribution in the

Table 1. Gini coefficients for ancestral ethnic group distribution in the four Changhua districts: 1901 and 1926.

\begin{tabular}{ccccc}
\hline & \multicolumn{2}{c}{ Changhua Street } & \multicolumn{2}{c}{ Xiushui Village } \\
\hline Year & 1901 & 1926 & 1901 & 1926 \\
Presence of Public Schools & 0.6339 & 0.6882 & 1.0000 & 0.9383 \\
\hline Year & \multicolumn{2}{c}{ Yuanlin Street } & \multicolumn{2}{c}{ Tianwei Village } \\
\hline Absence of Public Schools & 1901 & 1926 & 1901 & 1926 \\
\end{tabular}


four Changhua districts calculated from the population proportion data in Figure 1.

According to the characteristics of the Gini coefficient, values closer to 1 indicate more centralized distributions whereas values closer to 0 express a greater uniformity. As for the ancestral ethnic group distribution of question in this article, a more centralized ancestral ethnic group distribution is represented by an increase in Gini coefficient; a decrease in the value indicates a more dispersed ancestral ethnic group distribution. Taking Changhua Street as an example, Table 1 shows the local Gini coefficient to be 0.6339 in 1901, which increased to 0.6882 in 1926 . Based on the property of the Gini coefficient, this means that the ancestral ethnic group distribution on Changhua Street became more centralized between 1901 and 1926. As another example, the value for Xiushui Village reduced from 1.0000 in 1901 to 0.9383 in 1926. This reduction reflects a dispersed trend in the ancestral ethnic group distribution at Xiushui Village. By combining this finding with the text description of population proportions for Changhua Street and Xiushui village in Figure 1, it is apparent that the changes in Gini coefficient at these two districts indeed reflected the trend of ancestral ethnic group distribution.

Although Figure 1 does not clearly indicate whether the ancestral ethnic group distribution of Yuanlin Street and Tianwei Village followed a centralized or dispersed trend, it is worthy to note that the trend can also be determined through changes in the Gini coefficient. The increase in Gini coefficient for Yuanlin Street demonstrates a centralized ancestral ethnic group distribution, where as the decrease for Tianwei village indicates a dispersed distribution. By following this logic, the ancestral ethnic group distribution at these two districts can be clearly determined. Hence, calculating the Gini coefficient can provide a full picture of the Han Chinese ancestral ethnic group distribution as described above.

Let us turn the focus back to the theme of this article-the effects of Japanese public school establishment on Taiwan's ancestral ethnic group distribution during the Japanese colonial period. In districts where public schools were established, Table 1 shows that Changhua Street had a centralized ancestral ethnic group distribution and Xiushui Village had a dispersed distribution. On the other hand, in districts where public schools were not established, Yuanlin Street showed a centralized distribution and Tianwei Village showed a dispersed distribution. Under such circumstances, did Japanese public school education during the Japanese colonial period "assimilate" different ancestral ethnic groups in Taiwan and change their distribution by altering the Han Chinese's unique clustering behaviors that had been formed since the Qing dynasty? Therefore, we present an observation of the public schools established across Changhua Plain districts in Figure 2.

Figure 2 shows the locations of each public school in Changhua Plain during the early Japanese colonial period before 1905. From Figure 2, it is clear that the 


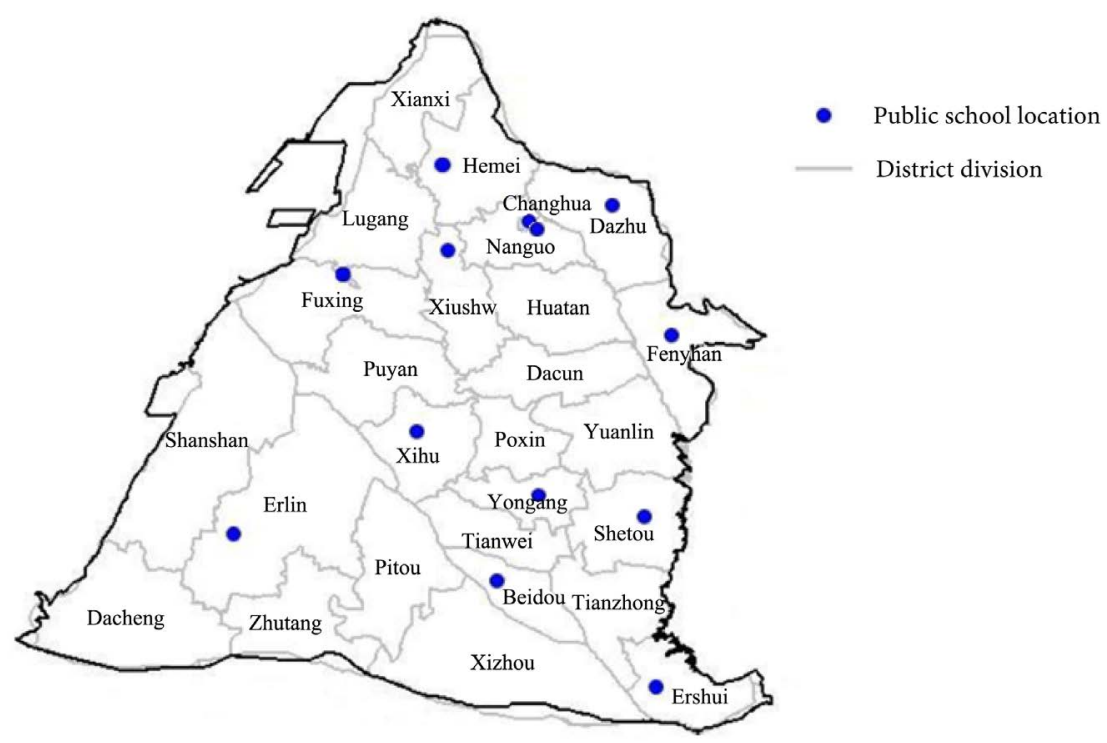

Figure 2. Public school locations in the Changhua area during the early Japanese colonial period. Data source: Academia Sinica (2003), Taiwan history and culture in time and space system.

public schools were distributed across the entire Changhua Plain, but they were not set up in every district. Among the 27 administrative districts in Changhua Plain, public schools were established in 13 of the districts but not in the other 14 districts. ${ }^{7}$

According to Section 1, Japan was keen to assimilate Taiwanese into Japanese and reduce their identification with the Chinese ancestral home. This idea became an education policy that was reflected by the establishment of public schools to promote Japanese education across Taiwan. However, the establishment of public schools in the early Japanese colonial period had to consider practical factors such as local public finance, economy, and school enrollment population. For example, in 1898 the Government-General of Taiwan formulated the "Public School Principles," stipulating that the National Treasury is only responsible for the faculty and staff wages. Other expenses for public school maintenance should be managed from local tax, local resident donation, and tuition. These regulations clearly set a limit on the number of public schools established (Chen, 2006). As shown in Figure 2, public schools were only established in less than half of the Changhua Plain districts before 1905. This is because public schools could only be established in places that can afford the school expenses. This made the promotion of Japanese education difficult in areas without public schools. As a result, it is possible to evaluate the effects of Japanese education on ancestral ethnic group distribution by comparing the differences in Japanese education implementation with regard to the presence or absence of public schools in various areas in Changhua Plain.

${ }^{7}$ There were 13 districts where public schools were established. There were Changhua Street, Lugang Street, Nanguo Village, Dazhu Village, Hemei Village, Xiushui Village, Fenyuan Village, Xihu Village, Yongjing Village, Shetou Village, Ershui Village, Beidou Street, and Erlin Village. 
The next section will provide a comparison between areas with and without public schools, and discuss whether public school establishment affected ethnic group distribution. Then, we will employ the difference-in-differences approach in discussing the above question.

\section{Difference-in-Differences Estimation}

In order to clarify whether public school establishment can "assimilate" different ancestral ethnic groups and thereby change ancestral ethnic group distribution, this section will estimate such effects by using the quantitative method of difference-in-differences model (hereafter abbreviated as DD). For this reason, this section will start with a discussion on the adequacy of applying DD to the current study.

Since we aim to explore the effects of public school establishment on ethnic group distribution through DD model estimation, it is necessary to compare the experimental group and control group side-by-side, and remove the fixed effect by using changes in the control group. However if the districts with public schools are set up as the experimental group, then the question is whether or not the districts without public schools can serve as an adequate control group. Geographically, Changhua Plain is a complete and independent area. Thus the various areas within Changhua should have similar economic social development. ${ }^{8}$ From the data perspective, we make the distinction between experimental and control groups based on public school establishment, and observe the 1901 ethnic group distribution in each area. As shown in Table 2, when alpha $=0.05$, the null hypothesis that both groups have an equal mean cannot be rejected. ${ }^{9}$ Therefore, it cannot be falsified that the experimental and control groups have the same mean ethnic group distribution. ${ }^{10}$ This shows that the distinction between experimental and control groups based on public school establishment should be adequate.

Other than comparing the experimental and control groups for adequacy, it is also important to consider the amount of time required for public school establishment to have an effect on ethnic group distribution. The public schools in the

${ }^{8}$ We follow Belasen and Polachek (2008) who used DD to estimate the effects of hurricane on Florida's labor market. The study believed that Florida's economic performance is shared by different counties in the state, thus it is possible to use counties that were not destructed by hurricanes as the control group for counties invaded by hurricanes. In line with this idea, this article uses the establishment of public schools as a criterion in classifying the experimental and control groups.

${ }^{9}$ Table 2 presents the basic statistics of both the experiment group and control group, such as their mean and variance. We can use Table 2 to calculate t-statistics and test whether the means of these two groups are equal. With differences in variance between the two groups, $t=0.8109$. Thus, the critical value is 2.0687 given alpha $=0.05$ and $\mathrm{DF}=23$. Hence we cannot reject the null hypothesis that both groups have an equal mean.

${ }^{10}$ The approach is referenced from a study by Card and Krueger (1993), which used DD to evaluate the effects of minimum wage on employment. The study compared the minimum wage in New Jersey on one side on Delaware River (experimental group) with Pennsylvania on the other side of Delaware River (control group). In order to convince readers about the feasibility of the DD method, the study also compared some mean features of fast food companies in the two states for significant differences. 
Table 2. The experimental and control groups for public school establishment and the basic statistics of 1901 Gini coefficients.

\begin{tabular}{|c|c|c|}
\hline & Experimental Group & Control Group \\
\hline District & $\begin{array}{l}\text { Changhua Street, Lugang Street, Nanguo Village, } \\
\text { Dazhu Village, Hemei Village, Xiushui Village, } \\
\text { Fenyuan Village, Xihu Village, Yongjing Village, } \\
\text { Shetou Village, Ershui Village, Beidou Street, } \\
\text { Erlin Village }\end{array}$ & $\begin{array}{l}\text { Xianxi Village, Fuxing Village, Huatan Village, } \\
\text { Yuanlin Street, Dacun Village, Puyan Village, } \\
\text { Poxin Village, Tianzhong Village, Tianwei Village, } \\
\text { Pitou Village, Shashan Village, Dacheng Village, } \\
\text { Zhutang Village, Xizhou Village }\end{array}$ \\
\hline Mean & 0.8597 & 0.8152 \\
\hline Variance & 0.0136 & 0.0274 \\
\hline
\end{tabular}

experimental group were established approximately between 1897 and 1905, during the early development of Japanese education in Taiwan. At that time, the students under Japanese education were still young. By 1926, those students had grown up. Their understanding about and identification with the ancestral home in southeast China coast might have weakened, and thereby affected the ancestral ethnic group distribution.

Therefore, we consider 1901 Gini coefficients as the levels of ancestral ethnic group distribution before Japanese public school education produced an effect. If Japanese public school education could change the clustering of ancestral ethnic groups in Taiwan and affect their levels of distribution, then the effect should be observable in the 1926 Gini coefficients. Thus, the effects of Japanese public school education on ethnic group distribution can be measured by comparing between the 1901 and 1926 Gini coefficients. In this article, the following econometrics model is designed under the DD approach:

$$
\begin{aligned}
\text { Gini }_{\text {it }}= & \alpha_{1} \text { Kogakko }_{i}+\alpha_{2} \text { After }_{t}+\alpha_{3} \text { Kogakko }_{i} \cdot \text { After }_{t}+\alpha_{4} \text { Density }_{i t} \\
& +\alpha_{5} \text { Gini_nei }_{i t}+\alpha_{6} \text { Quan }_{i t}+\alpha_{7} \text { Zhang }_{i t}+\alpha_{8} \text { Conton }_{i t}+\varepsilon_{i t}
\end{aligned}
$$

The subscript $i$ in the above formula denotes each district, and $t$ represents time. The dependent variable on the left of the equal sign is the Gini coefficient $\left(G_{i n i}\right)$. In the following order, the independent variables on the right of the equal sign are: dummy variable for public school establishment before 1905 $\left(K_{\text {ogakko }}\right)-1$ represents the presence and 0 represents the absence of Japanese public schools; dummy variable for year $\left(\right.$ After $\left._{t}\right)-1$ represents 1926 and 0 represents 1901; interaction term of two dummy variables $\left(\right.$ Kogakko $_{i} \cdot$ After $\left._{t}\right)$-the parameter estimate of this variable $\hat{\alpha}_{3}$ is the key of this article; some other control variables for each district such as the population density ( Density ${ }_{i t}$ ), mean Gini coefficients for nearby districts ( $G i n i \_n e i_{i t}$ ), dummy variables for main ethnic groups $\left(\right.$ Quan $_{i t}$, Zhang $_{i t}$, Conton $\left.{ }_{i t}\right),{ }^{11}$ and error term $\left(\varepsilon_{i t}\right)$.

\footnotetext{
${ }^{11}$ The main ancestral ethnic group in a district is represented by the ethnic group that accounts for the greatest proportion of the total population. For example, the Quanzhou group accounts for the greatest population proportion in the area, then $\operatorname{Quan}_{i t}=1$, otherwise it would 0 . When the Zhangzhou group accounts for the greatest proportion, Zhang $_{i t}=1$, otherwise it is 0 . When Guangdong descendants accounts for the greatest proportion, Conton $_{i t}=1$, otherwise it is 0 . Under such setting, we uses ancestral home other than Quan, Zhang, and Guangdong as a reference to avoid the problem of collinearity.
} 
After making the classification between experimental and control groups based on public school establishment through DD model setup, the controls groups between 1901 and 1926 are compared to determine the fixed effect for removal from the experimental group: ${ }^{12}$

$$
\begin{aligned}
& \left\{E\left[\text { Gini }_{i t} \mid \text { Kogakko }_{i}=1, \text { After }_{t}=1\right]-E\left[\text { Gini }_{i t} \mid \text { Kogakko }_{i}=1, \text { After }_{t}=0\right]\right\} \\
& -\left\{E\left[\text { Gini }_{i t} \mid \text { Kogakko }_{i}=0, \text { After }_{t}=1\right]-E\left[\text { Gini }_{i t} \mid \text { Kogakko }_{i}=0, \text { After }_{t}=0\right]\right. \\
& =\left\{\alpha_{1}+\alpha_{2}+\alpha_{3}-\alpha_{1}\right\}-\left\{\alpha_{2}\right\}=\alpha_{3}
\end{aligned}
$$

In the above formula, the curly brackets at the front represent changes in Gini coefficients for the districts with public schools (experimental group). These changes may include the fixed effect from the progression of time. Hence the fixed effect needs to be measured from the control group with no public schools (the curly brackets at the end) for removal, in order to obtain the actual effects of public school establishment on ancestral ethnic group distribution. Based on the DD model design in this article, the effects of public school establishment on ethnic group distribution can be estimated through the parameter estimate $\hat{\alpha}_{3}$ of the interaction term $\left(\right.$ Kogakko $_{i} \cdot$ After $\left._{t}\right)$. This is why the parameter estimate $\hat{\alpha}_{3}$ is the main focus of this article.

The results of estimation are shown in Table 3. Let us start with a look at the five control variables Density ${ }_{i t}$, Gini_nei $i_{i t}$, Quan $_{i t}, Z_{\text {hang }}$ it, and Conton ${ }_{i t}$. Under the more rigorous significance level alpha $=0.05$, all variables other than the parameter estimates of Gini_nei ${ }_{i t}$ and $Q_{u a n_{i t}}$ do not reach the significance level. However, when the significance level is slightly relaxed to alpha $=0.1$, the parameter estimates of Gini_nei $i_{i t}$, Quan $_{i t}, Z_{\text {Zhang }}$, , and Conton $_{i t}$ all reach the significance level. Looking at the parameter estimates of the three dummy variables Quan $_{i t}$, Zhang ${ }_{i t}$, and Conton ${ }_{i t}$, the Quanzhou population is considered as the more superior ethnic group with a more centralized distribu-

\begin{tabular}{|c|c|c|c|c|}
\hline & & & $F$-statistic & 221.6560 \\
\hline & & & Prob $>F$ & 0.0000 \\
\hline Variable & Parameter Estimate & Standard Error & $t$-statistic & $p$-value \\
\hline$K_{\text {Kogakko }}$ & 0.0802 & 0.0572 & 1.4029 & 0.1675 \\
\hline After $_{t}$ & 0.0058 & 0.0555 & 0.1043 & 0.9174 \\
\hline Kogakko $_{i} \cdot$ Aftert & 0.0087 & 0.0818 & 0.1060 & 0.9160 \\
\hline Density $_{\text {it }}$ & -0.0002 & 0.0002 & -1.0204 & 0.3130 \\
\hline Gini_nei $i_{i t}$ & 0.6457 & 0.1431 & 4.5119 & 0.0000 \\
\hline${Q u a n_{i t}}$ & 0.3108 & 0.1245 & 2.4960 & 0.0163 \\
\hline Zang $_{\text {it }}$ & 0.2188 & 0.1223 & 1.7889 & 0.0804 \\
\hline Conton $_{i t}$ & 0.2245 & 0.1311 & 1.7117 & 0.0938 \\
\hline
\end{tabular}
tion than other ancestral home populations (including Zhangzhou, Guangdong)

Table 3. Results of estimation from the DD model.

${ }^{12}$ Please refer to Angrist and Pischke (2009) for the interpretation of DD. 
regardless of public school establishment; it is followed by Guangdong and next by Zhangzhou populations. ${ }^{13}$ In general, the F-statistic $=221.656$ is statistically significant when applying the F-test to the significance of the overall DD model coefficient. Hence, the DD model designed in this article is fairly adequate.

In addition, the parameter estimates for public school establishment ( Kogakko ${ }_{i}$ ), year progression $\left(A f t e r_{t}\right)$, and interaction term $\left(\right.$ Kogakko $_{i} \cdot$ After $\left._{t}\right)$ are all positive numbers but they are not significantly different from zero. A combination with the data we collected and Table 3 shows that public school establishment brought ancestral group centralization $\left(\hat{\alpha}_{1}=0.0802\right)$. As time passed by, the trend of ancestral group centralization also became more apparent $\left(\hat{\alpha}_{2}=0.0058\right)$. However, it should be noted that neither of the above parameter estimates reached significance under the econometrics model analysis.

As the main parameter estimate of this article, $\hat{\alpha}_{3}=0.0087$ does not reach the significance level, representing a lack of sufficient statistical evidence to support or falsify whether Japanese education created an impact on ethnic group distribution in Taiwan. This means that the effects of Japanese public school education on Taiwan's ethnic group distribution remain unclear.

However, from the perspective of Ziliak and McCloskey (2004), statistical significance is not the most important factor. Instead, the emphasis should be placed on economic significance. This means that the model estimated values should be the primary focus. Based on this idea, the estimate of $\hat{\alpha}_{3}=0.0087$ which suggests that public school establishment led ancestral ethnic group distribution toward a centralized direction. Since the value of $\hat{\alpha}_{3}$ is quite small, Japanese public school education can be considered to have very small and insignificance effect on ethnic group distribution in Taiwan.

\section{Conclusion}

Based on the above description, Table 3 at the end of Section 3 concludes that the value of parameter estimate $\hat{\alpha}_{3}$ is very small and it does not reach the significance level. However, the statistical evidence above can provide the following information.

Japanese public school education could not affect the clustering of Han Chinese in Taiwan long since the Qing dynasty. We attribute this observation to the effects of Han Chinese features in traditional Taiwanese families. According to the records at the time, most people still spoke Fujian or Hakka dialects at home as they only spoke Japanese at public schools (Hsu, 2005). Although the public schools focused on Japanese education and did not teach any ancestral home culture, an understanding of such knowledge was still preserved in the daily life of Taiwanese families. It brought the power of ancestral ethnic groups together and formed ancestral ethnic group clustering. This statistically insignificant ob-

\footnotetext{
${ }^{13}$ By Figure 1 which is a graphical presentation of the data collected, in areas that were mainly populated by Quanzhou populations (such as Xinshui Village), it can be seen that the levels of centralization were more obvious compared to other ancestral groups.
} 
servation also serves as a depiction of such historical backgrounds.

Furthermore, the low school enrollment rate at public schools in Taiwan might also be one of the factors in producing the insignificant effects. Back then, Japanese public school education was not intended for general Taiwanese residents; it was only available to the middle-upper class. In other words, Japanese public school education was not universal for every resident, and the enrollment rate in Taiwan was significantly lower than that in Japan (Wu, 1992). Overall, there was a lack of popularity and proactivity in the Taiwanese people's response to Japanese public school education during the early Japanese colonial period. Hence the effects of public schools on ancestral ethnic group distribution should have been weak and unapparent. The estimation $\hat{\alpha}_{3}$ also provides a glimpse of understanding to this type of historical factors.

It appears that Japanese public school education had insignificant effects on Taiwan's ancestral ethnic group distribution during the Japanese colonial period. In addition to the many factors that can pass on traditional Han Taiwanese features described above, there are also other economic factors to discuss and elaborate on. The land system is an obvious example. Looking at the history of land development in Taiwan, the economy has always been dominated by the landlord-tenant system. Without a doubt, this system had closely bound the people and the land together. When people mostly depended on the land for income, ancestral ethnic group clustering based on land ownership could have been formed as early as the Qing dynasty in Taiwan. Under Japanese rule, although the Government-General of Taiwan abolished the dual-landlord system, the collaboration with landlords still remained in place. ${ }^{14}$ In other words, the distribution of Han ancestral ethnic groups in Taiwan during the Japanese colonial period followed the trends from the Qing dynasty. It could not be easily changed at once and it was not something that could be shaken by Japanese public school education.

The limitations of research in our study should be specially mentioned. The ancestral group distribution since the Qing dynasty was formed over a long process by many factors including the society, economy, and history. In focusing on the effects of public school on ancestral group distribution in Taiwan during the Japanese colonial period, the econometrics model adopted in this study only showed the statistical effects rather than the full picture. Ancestral home identification has many levels and facets-looking at it from the single perspective of ancestral group distribution may pose a narrow view. Therefore, we plan to follow up on the study by further discussing ancestral home identification from different perspectives.

\section{Conflicts of Interest}

The author declares no conflicts of interest regarding the publication of this paper.

${ }^{14}$ Yanaihara (1929) provides a clear logic for the limitation and prematurity of Japanese capitalism in Taiwan. 


\section{References}

Academia Sinica (2003). Taiwan History and Culture in Time and Space System. Taipei: Academia Sinica.

Angrist, J. D., \& Pischke, J. S. (2009). Mostly Harmless Econometrics: An Empiricist's Companion. Princeton, NJ: Princeton University Press. https://doi.org/10.1515/9781400829828

Belasen, A. R., \& Polachek, S. W. (2008). How Hurricanes Affect Wages and Employment in Local Labor Markets, American Economic Review, 98, 49-53. https://doi.org/10.1257/aer.98.2.49

Card, D., \& Krueger, A. B. (1993). Minimum Wages and Employment: A Case Study of the Fast Food Industry in New Jersey and Pennsylvania. Cambridge, MA: National Bureau of Economic Research. https://doi.org/10.3386/w4509

Chen, P. -F. (2006). The Different Intentions behind the Semblance of "Douka": The Language Policy, Modernization and Identity in Taiwan during the Japan-Ruling Period. Taipei: Cite Publishing.

Government-General of Taiwan (1902). Investigations on Formosa Development and History. Taipei: Taiwan Sotokufu Archives.

Hsu, P. -H. (2005). The Modern School in the Colony Taiwan. Taipei: Yuan-Liou Publishing.

Hsu, S. -R. (2003). The First Features of Taiwanese Ancestral Places and Ethnic Distributions in the Beginning of the 20th Century: Graphical Presentation of the Statistic Data from Relative Investigations of Formosa Development and History by the Taiwan Sotokufu in 1901. Journal of Geographical Research, 59, 91-126.

Iceland, J., Weinberg, D. H., \& Steinmetz, E. (2002). Racial and Ethnic Residential Segregation in the United States: 1980-2000. Washington DC: U.S. Government Printing Office.

Investigation Office of Government-General of Taiwan (1928). Investigation of Han Ancestral Home in Taiwan. Taipei: Investigation Office of Governor-General of Taiwan.

Komagome, T. (1996). Cultural Integration of the Japanese Colonial Empire. Tokyo: Iwanami Shoten.

Lin, H. (1870). Notes on East Sea. Taiwan Collectanea No. 8, Taipei: Bank of Taiwan.

Taiwan Self-Governance Association (1943). Streets and Villages. Taipei: Taiwan SelfGovernance Association.

Tu, Z. Y. (1975). Taiwan under Japanese Imperialism. Tokyo: University of Tokyo Press.

Wu, W. -H. (1992). A Study of Taiwanese Social Leadership under Japanese Rule. Taipei: Zhengzhong Publishing.

Yanaihara, T. (1929). Taiwan under Imperialism. Tokyo: Iwanami Shoten.

Ziliak, S. T., \& McCloskey, D. N. (2004). Size Matters: The Standard Error of Regressions in the American Economic Review. The Journal of Socio-Economics, 33, 527-546.

https://doi.org/10.1016/j.socec.2004.09.024 